\title{
Impact of Benefits and Barriers of Implementing Human Resources Information System on Staff Performance at Al-Balqa Applied University
}

\author{
Mohammad Izzat Alhalalmeh ${ }^{1}$ \\ ${ }^{1}$ Business Administration, Al-Balqa Applied University, Princess Alia University College, Jordan \\ Correspondence: Mohammad Izzat Alhalalmeh, Business Administration, Al-Balqa Applied University, Princess \\ Alia University College, Jordan. E-mail: dr.alhalalmeh@bau.edu.jo
}

Received: June 25, 2018

Accepted: August 18, 2018

Online Published: September 6, 2018

doi:10.5539/ijbm.v13n10p47

URL: https://doi.org/10.5539/ijbm.v13n10p47

\begin{abstract}
The study objectives are to investigate the influence of human resources information system benefits and barriers on staff performance in Al-Balqa applied university. To fulfill such objectives, a self-administrated questionnaire was used for the purpose of collecting the required date. The questionnaire was distributed over the research sample that was consisted of 200 subjects selected randomly. Descriptive methodology was use. Collected data were analyzed through using the SPSS. The research concluded that human resource information system implementation impacts positively university performance. The results also revealed that an implementation human resource information system barrier affects negatively university staff performance.
\end{abstract}

Keywords: human resources, information system, staff performance

\section{Introduction}

Information systems and technology need has become one of major elements for organizations success due to their importance role in making right decisions. In addition information technical development has also become one of knowledge development pillars for the purpose of making right decisions.

Absence of correct information is deemed when required as an important factor that causes administrative decisions failure, including strategic planning processes and organizations future policies .Therefore, it is a system that is used to prepare detailed functions and capabilities statement and how they can be developed develop. In the same time it refers to define objectives and policies for the purpose of using available human resources to measure organization's achievement of its objectives.

\subsection{Problem Statement}

The problem of the study is to identify the benefits and barriers of the use of human resources information systems at Al-Balqa applied university, which is directly or negatively reflected on university performance because the human element is one of the most important resources in the university and therefore the problem of research becomes more clearly by asking the following questions :

- Is there any impact of benefits of using human resources information system on staff performance at AlBalqa Applied University?

- Do barriers in using human resource information system impact staff performance at Al-Balqa University?

\subsection{Research Objectives}

The study aims at investigating the barriers at Al-Balqa Applied University that face in implementing human resources information system.

It also aim sat investigating the following objectives:

1. To find out the problems associated with human resources information system at Al-Balqa Applied University.

2. To specify the challenges of implementing human resources information system at Al-Balqa Applied University. 
3. To recommend some procedures to avoid such barriers in implementing.

\subsection{Research Importance}

Al-Balqa Applied University is one of the most popular public universities in Jordan. This indicates the need for information systems capable of meeting the requirements of the university. Therefore, this research on using benefits and barriers that hinder the use of human resources information system is important in general.

\section{Literature Review}

The system is a group of elements that are integrated with the common purpose of achieving an objective (Macleod \& Schell, 2001, p. 9). An information system can be defined as a "set of interrelated components that collect (or retrieve), process, store, and distribute information to support decision making, coordination, and control in an organization". Human resources information system is an integrated database of pertinent information on people and positions that can aid managers in evaluating the present status of the human resources in their organization, formulating objectives for activities relevant to human resources, and evaluating the success of those activities at a future date (Lauden \& lauden, 2002). Human Resource Information System is "a systematic way of storing data and information for each individual employee to aid planning, decision making, and submitting of returns and reports to the external agencies. HRIS can be briefly defined as integrated systems used to gather, store and analyze information regarding an organization's human resources". Hendrickson and Mondy (2013) defined human resources information system as "organizations approach of to obtain information on which human resources can rely in decision-making, and it is an umbrella for integrating various subsystems". In this context Singh (2011) defined human resources information system as "a system that stores data, records and all information about employees, usually through databases or a series of interconnected databases".

Many studies has tackled barriers and benefits of implementing human resources information systems for example Sabrina argued that information technology is used in every field, and thus organization's success depends on effective utilization of its human resources. Since ,human resources now are deemed as strategic assets... Nowadays organizations are using human resources information system for the purpose of ensuring effective utilization of their human resources. According to Ngai et al. (2008) human Resource Information System is used by organization to collect and maintain data that are used to describe human resources, transforming into information and then reporting the data information to users. In this context, Gill and Johnson (2010) indicated that human Resource Information System is a "method that utilizes the knowledge-based technology for human resource functions management and applications". It is a system that concern with employees issues and their employment specific information. Mohammad and Islam (2017) found, that, High investment, Costly maintenance, Long-term benefit, Organizational Structure, Culture of the Organization, Top management support, lack of experts and user, are major barriers in implementing human resources information system .Beckers and Bsat (2002) stated that high cost in maintenance is considered as one of the main barriers that hinder human resources information system implementation. Batool et al. (2012) indicated that shortage of funds and untrained employees are major types of barriers of implementing human resources information systems. Delorme and Arcand, (2010) found that the main barrier to implement human resources information systems is the absence of good qualified human resources information systems employees, challenges with time management, the necessity to figure with alternative departments, and therefore lack of IT support. Some studies on information technology adoption and implementation have indicated difficult technologies, like human resources information systems applications, perceived obstacles are relevant as a result of the adoption method tends to .Shine et al. (2015) in his study revealed many challenges that hinder human resource information system implementation effectively Nisha et al. (2014) examined university teaching staff's perception regarding many issues such as functions, benefits and barriers of human resource information system . The research results revealed that human resources information are used for administrative purpose. Sabrina (2014) who has analyzed the small corporate houses and big organizations, failed to realize the benefits of HRIS.

Gupta (2013) indicated that human resources information system used provide increase leaps in efficiency. He added time of many human resource jobs responses are traditionally labour intensive. The human resources information system causes reduction in efforts duplication and in organizing the human resources staff efforts of. The main benefit of human resources is the ability of developing and managing employees continuously. With respect to organizations human resources systems improve employee's job productivity through eliminating work repetition and speeding. Organizations today face operation cost reduction pressure in addition to be responsive to meet customers' demands. The use of human resource information systems leads to good results for organization due to the benefits it provides the organization such as decreasing costs, improving communication and time decrease time for accomplishing human resources related activities (Beadles et al., 
2005).

Human Resource Information System collects and maintains organization human resources, transforming data into information and then reporting the information to users. Human resources information system usage would reduce the costs of human resources through automating information and reducing the need for large numbers of human resources employees; by helping them to control their personal information; and by providing managers to access relevant information and data, conduct analysis, decide, and communicate with others without consulting and human resource professional (Shine et al, 2015).

\section{Objectives of human Resources Information System}

Human Resources Information System aims to achieve the following objectives:

A) Collect relevant information to all the functions and requirements of the Organization in terms of experience and qualifications and store laws, regulations and instructions relating to personnel matters of the Organization for reference when necessary.

B) To provide the Department with data and information collected for the purpose of using such data in the preparation of plans, policies and programs for selection, appointment, evaluation, training, development, salaries, wages and incentives.

C) To provide research departments and organizational studies with data and information collected as necessary for the purpose of preparing research and studies managed by human resources with activities

D) Providing managers with the data and information collected to be used to assess the performance of the staff of the institution and to make decisions on employee's mobility and promotions.

E) Maintains all applicants' information and choose individuals using the information mentioned in the form of an application to work for the purpose of developing the registry and avoiding duplication of data entry.

F) To accelerate data retrieval and processing, data classification and reclassification, to improve information analysis, leading to more effective decisions, better working culture, a more transparent system and a stable system.

G) To maintain a complete database and update itself for use in preparing required reports, maintaining records and automating routine tasks.

Jahan (2014) noted that HRIS is one of the major new HR tools. At present, the human resources information system has become commonplace. The main barrier to the implementation of the Human Resources Information System (HRIS) was the lack of administrative support and high cost. But the benefits of HRIS are more than barriers.

Singh (2011) specifies users of HR information system into three groups:

1. Professionals: Human resources are professionally dependent on human resources and their use in functional performance (eg. regulatory reporting, compliance, compensation analysis, payroll, dividend management and skill stock). Depends on, relies on professional human resources on the human resources information system to perform the majority of functions and work tasks.

\section{Directors of different organizational divisions:}

The management of the organization depends on the ability of human resources information systems to provide and analyze various data collected, especially in management, evaluation and performance, as well as use in skills testing, development, training, recruitment and retention of existing and new employees.

3. Organization staffs have become the ultimate users of almost all human resources information systems, all human resource applications and difficulties created for staff, but the benefits and options created by the system and the need to monitor and modify frequently selected variables Increase staff awareness. The importance and capacity of human resources information systems on their use

Human Resources Information System is used to collect and compile data describing human resources, converting data to information and then communicating information to users (Ngai et al., 2008).

\section{Methodology}

The research used primary and secondary data. The secondary data were collected from various resources such as: books, references, journals, thesis and previous articles that tackle the research topic. With respect to primary data, its collection was made through a survey that was distributed over employees who are working in human resources department in various colleges of Al-Balqa Applied University. The study used the purposive sampling 
technique to select sample's members the study sample consisted of 200 respondents.

\subsection{Data Collection Methods}

Two types of data collection are used. Secondary data and primary data, Collection of secondary data collection methods include every data resource that is available to researcher to facilitate obtaining the information needed for purposes of the research.

\subsubsection{Secondary Data}

Secondary data was collected for the purpose of solving the problem which the research is handling; the data were collected from various resources such as: books, journals, newspapers, periodicals, and the web net to collect the required secondary data.

\subsubsection{Primary Data Collection}

A self-administrated questionnaire was used to collect the needed primary data. The questionnaire was designed based on the previous studies. 5-points Likert scale, was used .The questionnaire consisted of three parts, started with the cover letter, the second part include the sample's personal data, while the third part includes all statement that measure independent variable in addition to the dependent variable.

\subsection{Population and Sampling}

The targeted population consists of human resource employees at Al-Balqa Applied University. A purposive sample was selected amounting (200) subjects.

\subsection{Research Instrument}

A self-administrated questionnaire was designed and distributed over the research sample. 200 questionnaires were distributed, all of which were collected.

\subsection{Reliability}

Cronbach alpha coefficient was carried out .The values obtained were (90.1) for benefits, (81.3) for barriers and (84.8) for the whole instrument.

\subsubsection{Descriptive Analysis}

Table 1 describing the sample's personal and demographic variables

Table 1. Sample's personal and demographic variables

\begin{tabular}{llll}
\hline Variable & Category & Frequency & Percent \\
\hline \multirow{2}{*}{ Gender } & Male & 96 & 48.0 \\
& Female & 104 & 52.0 \\
\multirow{3}{*}{ Age } & Less than 30 & 60 & 30 \\
& 30 - to less than40 & 80 & 40 \\
\multirow{5}{*}{ Education Level } & $40+$ & 60 & 30 \\
& Diploma degree & 50 & 25 \\
& Bachelor's degree & 130 & 65 \\
& Higher Studies & 20 & 10 \\
\hline
\end{tabular}

Table 1 indicated that males consist $48 \%$ of the total sample, while females consist $52 \%$. With respect to age $30 \%$ of the sample their age is less than 30 years, $40 \%$ of the sample their age ranges between 30 to less than 40 years, and finally $30 \%$ of the sample their age is more than 40 years. As for education level $25 \%$ of the total samples have diploma degree, while $65 \%$ of the total samples have bachelor's degree, and finally $10 \%$ of the total sample have higher studies.

The analysis indicated that means and standard deviation values for statements that measure benefits of human resources information systems ranged from medium to high scores. This means that human resources information system provides the university with many benefits such as reducing errors, aiding in making informal decisions, reducing requirement of man power, helping in standardizing the procedures, improving information control, minimizing paperwork, improving recruiting process, and providing quick responses. 
.In the same time the analysis indicated that there are some barriers that the university face in implementing the human resources information system represented by lack of top management support, lack of information technology experts, insufficient financial support, employee'resistance ,high costs.

\subsection{Hypotheses testing}

H01. There is no statistically significant impact of benefits of implementing human resources information system on staff performance at Al- Balqa Applied University.

Table 2. Model validity

\begin{tabular}{llllll}
\hline Variables & R & R Square & Std. Error of the Estimate & F & Sig \\
\hline Benefits & .354 & .125 & .61285 & 37.150 & .000 \\
\hline
\end{tabular}

Table 2 indicated that $\mathrm{F}$ calculated value $=37.150$ is more that tabulated $\mathrm{F}$ and $\mathrm{Sig}$ value is $(0.000)$ which is less than $(\alpha-0.05)$, which means the validity of simple regression, so there is an impact of benefits of implementing human resources information system on staff performance at Al- Balqa Applied University. Therefore it is possible to use the multiple regressions for measuring the impact of benefits.

Table 3. Regression coefficient for the first sub- hypothesis

\begin{tabular}{|c|c|c|c|c|c|}
\hline \multirow[b]{2}{*}{ Model } & \multicolumn{2}{|c|}{ Un standardized Coefficients } & \multirow{2}{*}{$\begin{array}{l}\text { SD Coif. } \\
\text { Beta } \\
\end{array}$} & \multirow[b]{2}{*}{$\mathbf{T}$} & \multirow[b]{2}{*}{ Sig. } \\
\hline & B & Std. Error & & & \\
\hline (Constant) & 2.373 & .139 & & 17.061 & .000 \\
\hline Staff performance & .248 & .041 & .333 & 6.095 & .000 \\
\hline
\end{tabular}

Table 3 results indicate that the regression coefficient $(\beta=0.333)$ for benefits is significant. Therefore there is a statistically significant impact at significance level $(\alpha=0.05)$ of benefits. T- Calculated (6.095) value confirms the impact Moreover the significant value $=0.000$ is less than the significant level $(\alpha=0.05)$. So null hypothesis is rejected and the alternative one is accepted. This means that there is a statistically significant impact of benefits of implementing human resources information system on staff performance at Al-Balqa Applied University

H02.There is no statistically significant impact of barriers of implementinghuman resources information system on staff performance at Al-Balqa Applied University.

Table 4. Model validity

\begin{tabular}{lllllll}
\hline Variables & R & R Square & Adjusted R Square & Std. Error of the Estimate & F & Sig \\
\hline Barriers & $.248^{\mathrm{a}}$ & .061 & .058 & .52689 & 19.512 & .000 \\
\hline
\end{tabular}

Table 4 indicated that F calculated value $=19.512$ is more that tabulated $\mathrm{F}$ and Sig value is $(0.000)$ which is less than $(\alpha-0.05)$, which means the validity of simple regression, so there is an impact of barriers of implementing human resources information system on staff performance at Al-Balqa Applied University. Therefore it is possible to use the multiple regressions for measuring the impact of benefits.

Table 5. Regression coefficient for the second sub hypothesis

\begin{tabular}{|c|c|c|c|c|c|}
\hline \multirow[b]{2}{*}{ Model } & \multicolumn{2}{|c|}{ Un standardized Coefficients } & \multirow{2}{*}{$\begin{array}{l}\text { SD Coif. } \\
\text { Beta }\end{array}$} & \multirow[b]{2}{*}{$\mathbf{T}$} & \multirow[b]{2}{*}{ Sig. } \\
\hline & B & Std. Error & & & \\
\hline (Constant) & 2.688 & .120 & & 22.386 & .000 \\
\hline
\end{tabular}

Table 5 results indicate that the regression coefficient $(\beta=0.248)$ for barriers is significant. Therefore there is a statistically significant impact at significance level $(\alpha=0.05)$ of barriers. T- Calculated (4.417) value confirms the impact Moreover the significant value $=0.000$ is less than the significant level $(\alpha=0.05)$. So null hypothesis is 
rejected and the alternative one is accepted. This means that there is a statistically significant impact of benefits of implementing human resources information system on staff performance at Al-Balqa Applied University.

\section{Conclusion and Recommendations}

The Human Resources Information System is essential for any organization for the purpose of ensuring effective management of persons and obtaining a competitive advantage. The Human Resources Information System will help the Department to make an effective and better decision. HR Information System is a very important for organization regardless of its activity. Provide different benefits for the organization. At the same time, the Organization is facing many obstacles in the implementation of the Human Resources Information System (HRIS).

It is worth to mention that HRIS implementation in general face may barriers due to the availability of those who resist new changes. Public sector organization such as Al- Balqa University faces many problems in implementing HRIS. So this reduces the benefits that can be obtained for implementing HRIS.

The research suggests that AL-Balqa Applied University should implement the human resources information system and keep pace with the latest developments in this field. Taking into account the benefits that may be gained in the implementation of the Human Resources Information System. In addition, the University is required to allocate funds for the implementation of human resources information systems and for the required manpower.

\section{References}

Barut, O., \& Dogerlioglu, O. (2010). Human Resources Information Systems. Socio technical Perspective Information Technology Journal, 9(5), 877-888.

Batool, S. (2012). Benefits and Barriers of Human Resource Information System in Accounts Office \& Azad Jammu \& Kashmir Community Development Program. International Journal of Humanities and Social Science, 2(3).

Beadles et al. (2005). The Impact of Human Resource Information Systems: An Exploratory Study in the Public sector. Communication of the IIMA, 5(4), 39.

Beckers, A., \& Bsat, M. (2002). A DSS classification model for research in human resource information systems. $\begin{array}{llll}\text { Information Systems } & \text { Management, } & \text { 19(3), }\end{array}$ https://doi.org/10.1201/1078/43201.19.3.20020601/37169.6

Delorme, M., \& Arcand, M. (2010). HRIS Implementation and Deployment: A Conceptual Framework of the New Roles, Responsibilities and Competencies for HR Professionals. International Journal of Business Information Systems, 5(2), 148-161. https://doi.org/10.1504/IJBIS.2010.030626

Gupta, B. (2013). Human Resource Information System (HRIS): Important Element of Current Scenario, OSR. Journal of Business and Management, 13(6), 41-46. https://doi.org/10.9790/487X-1364146

Hendrickson, A. R. (2003). Human Resource Information Systems: Backbone Technology of Contemporary Human Resources. Journal of Labor Research, 24, 381. https://doi.org/10.1007/s12122-003-1002-5

Laudon, K., \& Laudon, J. (2002). Management Information Systems (7th ed.). USA: Prentice Hall.

Macleod, R. Jr., \& Schell, G. (2001). Management Information Systems (8th ed.). USA: Prentice Hall.

Mohammad, A. R., \& Md. A. I. (2017). Barriers in Adopting Human Resource Information System (HRIS)An Empirical Study on Selected Bangladeshi Garments Factories. International Business Research, 10(6).

Mondy, R. W. (2013). Human Resource Management. Prentice Hall.

Ngai, E., Law, C., Chan, S., \& Wat, F. (2008). Importance of Internet to human resource PR actioners in Hong Kong, Personnel Review, 37(1), 66-84. https://doi.org/10.1108/00483480810839978

Nisha, B. U., Kumar, B. V., \& Sahay, M. T. (2014). Usage, benefits and barriers of human resource information system in universities. The Journal of Information and Knowledge Management Systems, 44(4), 519-536. https://doi.org/10.1108/VINE-04-2013-0024

Sabrina, J. (2014). Human Resource Information System (HRIS): A Theoretical Perspective. Journal of Human Resource and Sustainability Studies, 2(2). https://doi.org/10.4236/jhrss.2014.22004

Shine, D., Surbhi, S., \& Shivangi, G. (2015). Barriers in Implementing Human Resource Information System in Organization. International Journal of Engineering Research and Management (IJERM), 2(5). 
Singh, H. P., Jindal, S., \& Samim, S. A. (2011). Role of Human Resource Information Systems in Banking Industry of Developing Countries. The First International Conference on Interdisciplinary Research and Development, Thailand.

\section{Copyrights}

Copyright for this article is retained by the author(s), with first publication rights granted to the journal.

This is an open-access article distributed under the terms and conditions of the Creative Commons Attribution license (http://creativecommons.org/licenses/by/4.0/). 